\title{
Correction to: LncMAPK6 drives MAPK6 expression and liver TIC self-renewal
}

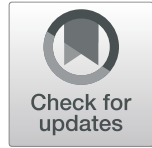

Guanqun Huang ${ }^{1 \dagger}$, Hui Jiang ${ }^{2 \dagger}$, Yueming He ${ }^{2}$, Ye Lin ${ }^{3}$, Wuzheng Xia ${ }^{3}$, Yuanwei Luo ${ }^{1}$, Min Liang ${ }^{2}$, Boyun Shi Xinke Zhou ${ }^{2^{*}}$ and Zhixiang Jian ${ }^{3^{*}}$

\section{Correction to: J Exp Clin Cancer Res https://doi.org/10.1186/s13046-018-0770-y}

In the original publication of this article [1], the author found an error in Fig. 2f. lncGPR107 should be changed to IncMAPK6, and the corrected Fig. 2 is shown below.

The author sincerely apologizes for the inconvenience caused to the readers.

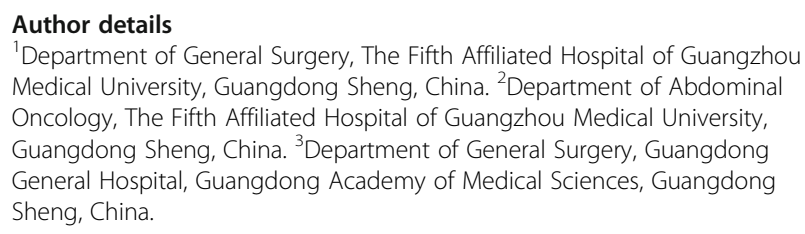

Published online: 20 December 2019

\section{Reference}

1. Huang G, et al. LnCMAPK6 drives MAPK6 expression and liver TIC selfrenewal. J Exp Clin Cancer Res. 2018;37:105. https://doi.org/10.1186/s13046018-0770-y.

\footnotetext{
The original article can be found online at https://doi.org/10.1186/s13046018-0770-y

*Correspondence: nihaeoj1465@126.com; sdf1984365@126.com

${ }^{\dagger}$ Guanqun Huang and Hui Jiang contributed equally to this work.

${ }^{2}$ Department of Abdominal Oncology, The Fifth Affiliated Hospital of

Guangzhou Medical University, Guangdong Sheng, China

${ }^{3}$ Department of General Surgery, Guangdong General Hospital, Guangdong

Academy of Medical Sciences, Guangdong Sheng, China

Full list of author information is available at the end of the article
}

(c) The Author(s). 2019 Open Access This article is distributed under the terms of the Creative Commons Attribution 4.0 International License (http://creativecommons.org/licenses/by/4.0/), which permits unrestricted use, distribution, and reproduction in any medium, provided you give appropriate credit to the original author(s) and the source, provide a link to the Creative Commons license, and indicate if changes were made. The Creative Commons Public Domain Dedication waiver (http://creativecommons.org/publicdomain/zero/1.0/) applies to the data made available in this article, unless otherwise stated. 


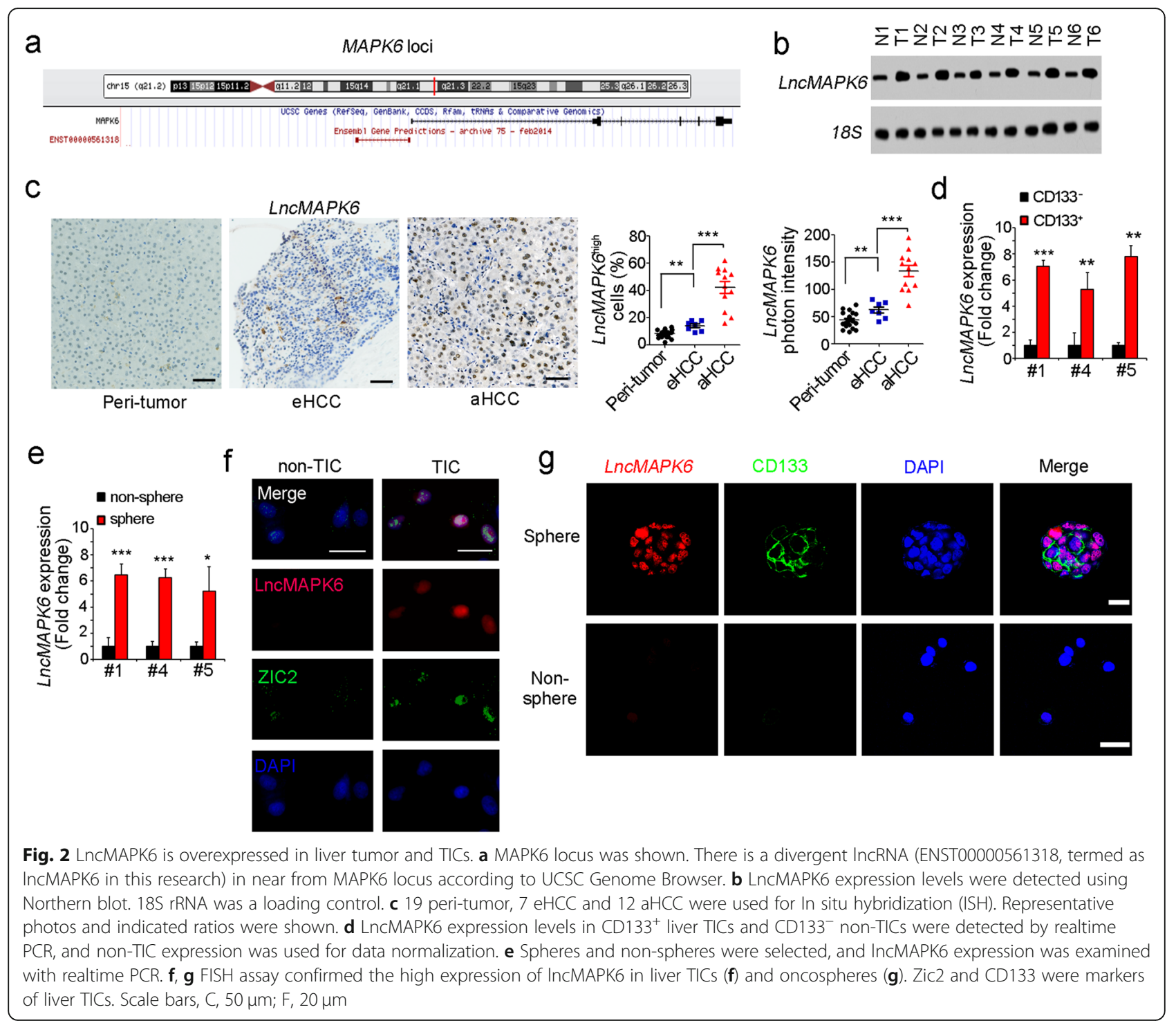

